\title{
Interaction between Merkel cell carcinoma and the immune system: Pathogenetic and therapeutic implications (Review)
}

\author{
IRENE ZANETTI, ILARIA COATI and MAURO ALAIBAC \\ Unit of Dermatology, University of Padua, I-35128 Padua, Italy
}

Received November 23, 2016; Accepted April 11, 2017

DOI: $10.3892 / \mathrm{mco} .2017 .1406$

\begin{abstract}
Merkel cell carcinoma (MCC) is a rare, aggressive primary cutaneous neuroendocrine carcinoma. It usually appears on the face and neck of elderly Caucasian people as a flesh-colored, erythematous or violaceous dome-shaped, non-tender nodule with a smooth surface. In immunocompromised patients with T-cell dysfunction, such as patients with acquired immunodeficiency syndrome (AIDS) or solid organ transplant recipients, the incidence of this disease is markedly increased. This suggests a link between the development of MCC and the immune system. Merkel cell polyolmavirus $(\mathrm{MCPyV})$ is clonally integrated into the majority of MCCs, suggesting its causative role in the pathogenesis of the majority of these tumors. Despite wide local excision, sentinel lymph node biopsy, and eventually, adjuvant radiation therapy, which remains the first-line treatment for MCC, the identification of MCPyV has opened novel therapeutic insights. Novel therapeutic strategies could be to inhibit MCPyV oncoproteins and to stimulate immune responses against virus-infected tumor cells by immunostimulatory cytokines, including interferons and interleukin-2.
\end{abstract}

\section{Contents}

1. Introduction

2. Clinical presentation

3. MCC and the immune system

4. MCPyV

5. Pathogenesis

6. Immunotherapy

7. Conclusions

\section{Introduction}

Merkel cell carcinoma (MCC) is a rare but aggressive primary neuroendocrine skin cancer, with a strong propensity to metastasize. It is considered to be caused by the malignant transformation of neurosecretory Merkel cells, which are located in the basal layer of the epidermis and are involved in skin mechanoreception (1). However, the origin of the malignancy of these cells remains a controversial issue. It is well known that MCC originates in the dermis, and only occasionally exhibits an epidermal involvement, whereas Merkel cells lay in the basal part of the epidermis; in addition, touch-sensitive areas, such as the lips and palmoplantar surfaces, are rich in Merkel cells, but it is unusual for MCC to originate in these locations (2). These findings demonstrate that the origin of MCC may not reside in the Merkel cells but, as recent studies have suggested, the origin of MCC may reside instead in pluripotent progenitor stem cells in the dermis (3) or in precursor B cells (4).

\section{Clinical presentation}

The clinical presentation of MCC is often non-specific: The clinical aspect of the lesion is usually a flesh-colored, erythematous or violaceous dome-shaped, non-tender nodule with a smooth surface. A differential diagnosis of MCC based on the clinical appearance includes such characteristics as epidermoid cysts, lipoma, basal cell or squamous cell carcinoma, amelanotic melanoma, pyogenic granuloma or lymphoma cutis. This skin cancer is characterized by an extremely rapid rate of growth, from a few weeks to months, leading in certain cases to ulceration (5). Typically, MCC arises in elderly Caucasians of either sex on sun-exposed skin. The most frequently affected site is the head and neck region (50\%), followed by the trunk $(30 \%)$ and the limbs (10\%), although MCC may arise in any body site, including the mucosae (6).

\section{MCC and the immune system}

MCC is an uncommon skin cancer, although its incidence is rising, probably due, on the one hand, to a higher level of detection via more advanced diagnostic techniques, such as cytokeratin 20 immunostaging (7), and on the other hand to the higher prevalence of MCC risk factors, including $\mathrm{T}$ cell

suppression and sun exposure (8). The annual incidence
Correspondence to: Professor Mauro Alaibac, Unit I-35128 Padua, Italy

E-mail: mauro.alaibac@unipd.it

Key words: Merkel cell carcinoma, immunity, skin cancer 
of MCC in the USA is $0.6 / 100,000$ per year, with a median age of 76.2 years for women and 73.6 years for men (9). Immunocompromised patients with T-cell dysfunction appear to be more likely to be affected by this disease: In these patients, the incidence of MCC is dramatically increased. For example, patients with acquired immunodeficiency syndrome (AIDS) have an incidence rate that is 11-13 times greater compared with the general population, and solid organ transplant recipients are 5-10 times more likely to develop MCC (10). There is also an association with ultraviolet (UV) radiation exposure: The incidence of MCC was determined to be 100 -fold greater in patients who underwent photochemotherapy (PUVA) treatment (11), and MCC usually affects sun-exposed areas, such as the head and neck region, whereas the trunk and the limbs are less commonly involved (6).

The higher susceptibility of immunocompromised patients, together with the positive association with UV exposure, suggests a link between MCC and the immune system. Furthermore, several case reports have described regression after an improvement in immune function, highlighting the importance of the immune system to the development of this cancer $(12,13)$.

This clear link with the immune system, particularly with T-cells, suggests that MCC may be caused by an infective agent. In 2008, Chang and Moore (14), using the technique of digital transcriptome subtraction, analyzed four samples of MCC and identified the 5,387-base-pair genome of an unknown polyomavirus that they termed 'Merkel cell polyomavirus' (MCV, or MCPyV). Furthermore, through the analysis of a further 10 samples, these authors demonstrated that MCPyV was clonally integrated in $80 \%$ of MCCs, suggesting that infection and integration occur prior to the clonal expansion of tumor cells, thereby underlining its oncogenic role (15). The remaining $20 \%$ of MCC is MCPyV-negative, and this is considered to be caused by a different oncogenic pathway that involves UV-induced DNA damage and chromosomal aberrations (16).

\section{MCPyV}

$\mathrm{MCPyV}$ is a non-enveloped, double-stranded circular DNA virus. It is found ubiquitously, and is frequently isolated from healthy subjects: The seroprevalence of this virus ranges from $9 \%$ in children under 4 years of age to $35 \%$ in teenagers (14), increasing to $80 \%$ in adults, suggesting that it may be part of the cutaneous microbiome (17). The means of transmission has yet to be fully elucidated: Assembled virions may be detected on clinically normal skin, suggesting a cutaneous transmission (18). However, MCPyV DNA has also been identified in the gastrointestinal tract, on oral and anogenital mucosa, and in respiratory secretions, supporting oro-fecal, trans-mucosal and respiratory means of transmission, respectively (19-23). $\mathrm{MCPyV}$ infection is asymptomatic, and this accounts for its high prevalence throughout the general population (24).

The MCPyV genome is made up of early and late gene regions separated by a non-coding regulatory region. The late gene region expresses the major capsid protein, VP1, and the minor coat proteins, VP2 and VP3, encoding the viral capsomere and capsid, whereas the early gene region encodes large $\mathrm{T}$ antigen (LT), $57 \mathrm{kT}$ antigen (57 kT) and small $\mathrm{T}$ antigen (sT) (16). The early gene region targets important cell proteins involved in cell cycle regulation and tumor suppression: LT interacts with the oncosuppressors, $\mathrm{p} 53$ and $\mathrm{pRB}$, whereas sT binds to protein phosphatase 2A (PP2A), which is involved in cell proliferation through the regulation of gene transcription. This explains why this region is termed the "tumor antigen locus'. In addition to this function, LT is also important in viral DNA replication: It is involved in the initiation of viral DNA synthesis through its origin binding domain (OBD), ATPase domain and helicase domain, which are localized in its carboxy-terminal part (25).

\section{Pathogenesis}

Following asymptomatic infection with $\mathrm{MCPyV}$, which usually occurs in early childhood, the immune system normally gives an appropriate humoral and cellular response. Thus, the virus becomes a part of the microbiome of the skin, from which it is chronically shed as encapsidated virions. UV radiation or other environmental mutagens, aging and infective or drug-induced immunosuppression are able to promote reactivation of the virus via the reduction in immunosurveillance. At this point, the viral genome is able to integrate into the host chromosome, courtesy of a defect in the virus itself, or following UV or mutagen exposure. In addition, a mutation in LT renders the virus unable to replicate (25). Indeed, $\mathrm{MCPyV}$ isolated from MCCs, in contrast with MCPyV from non-tumor sources, has been revealed to present mutations that are responsible for the premature truncation of the MCV LT helicase. These mutations do not affect the Rb binding domain, but eliminate the capacity of the viral DNA to replicate. In this way, the virus loses its capability to replicate in MCC tumoral cells, but continues to express motifs that may potentially lead to uncontrolled proliferation (26). Furthermore, sT is required for tumor cell proliferation, since sT knockdown inhibits cell replication in MCC (27). It has been revealed that sT prevents the dephosphorylation of the cellular translation factor, eIF4E-binding protein 1 (4E-BP1); hyperphosphorylated 4E-BP1 releases eIF4E, promoting active cap-dependent translation. Therefore, viral integration into the host genome and LT truncation mutations suggest that MCPyV may be responsible for MCC carcinogenesis via a 'hit-and-run' mechanism of transformation (25).

\section{Immunotherapy}

Currently, a wide local excision with at least a $1 \mathrm{~cm}$ margin, sentinel lymph node biopsy and, eventually. adjuvant radiation therapy are recommended by the National Comprehensive Cancer Network (NCCN) guidelines (28) as the first-line treatment for MCC. However, the identification of MCPyV in patients with MCC opened up novel therapeutic insights: On the one hand, the possibility to develop antiviral therapies interfering with the function of the oncoproteins, and on the other hand, the stimulation of immune responses against virus-infected tumor cells by immunostimulatory cytokines, such as interferons (IFNs) or interleukin-2 (IL-2) (24).

The proapoptotic action of IFN types I and II is well established (29). In particular, type I IFN is able to induce apoptosis in $\mathrm{MCPyV}^{+} \mathrm{MCC}$ cell lines in vitro and in vivo through the modulation of the virally encoded LTA: IFN type 
I reduces the expression of the MCV LT and increases the expression of promyelocytic leukemia (PML) protein, which interferes with the function of the LT (30). Furthermore, a multicenter study revealed that isolated hyperthermic limb perfusion with tumor necrosis factor- $\alpha$, IFN- $\gamma$, and melphalan resulted in a complete or partial response of locally advanced MCC (31).

Recombinant IL-2 causes regression of solid tumors by enhancing $\mathrm{T}$ cell activity, and it has already been approved by the Food and Drug Administration (FDA) for the treatment of metastatic melanoma and metastatic renal cell carcinoma (32). Regarding the treatment of metastatic MCC, a phase I/II clinical trial with autologous T cells and IL-2 (aldesleukin) is currently under way (33).

An alternative method of treatment would be to inhibit the downregulation of $\mathrm{T}$ cell function. An example of a group of agents that would be effective for this purpose is the cytotoxic T-lymphocyte-associated protein 4 (CTLA-4) blockers, such as ipilimumab; a randomized clinical trial has been set up that compares therapy with ipilimumab with observations made following surgical resection of MCC (34). CTLA-4 is a negative regulator of T-cell-mediated antitumor responses, and it is expressed only on T cells (35).

Other putative target therapy agents are programmed death-1 (PD1; CD279) and programmed death ligand-1 (PDL1) blockers. PD1, expressed on T cells but also inducible in B-cells and natural killer (NK) cells, after binding with its ligand, PDL1, is expressed only on tumor cells, thereby down-regulating $\mathrm{T}$ cell function (35).

Since CD56 is expressed on almost all MCC tumors, a phase I clinical trial has examined the use of the CD56-targeting antibody drug, IMGN901 (36); this molecule is a monoclonal antibody, made up of a CD56-binding domain attached to emtansine (DM1), a cytotoxic agent. Following its binding to CD56, IMGN901 is internalized into the cell and DM1 is released, thereby killing the cancer cell via inhibition of the polymerization of tubulin (36).

One difficulty that must be circumvented in this type of tumor is chemoresistance. One of the major mechanisms of MCC chemoresistance is inhibition of apoptosis through the upregulation of survivin (a member of the family of inhibitor of apoptosis proteins) and B-cell lymphoma 2 (Bcl-2) protein (37). In this situation as well, target therapy may help in fighting chemoresistance: YM-155, a novel small-molecule survivin suppressant, appears to downregulate survivin expression, promoting apoptosis in MCC xenograft tumors (38). A Bcl-2 antisense oligonucleotide has been demonstrated to arrest tumor growth in an MCC xenograft animal model, although a different Bcl-2 antisense oligonucleotide, G3139, did not exhibit any therapeutic efficacy in MCC (39). In addition, other apoptotic inhibitors, such as ABT-263, have demonstrated a certain level of clinical efficacy (40).

Following the identification of MCPyV, a novel and promising therapeutic approach would appear to be viral antigen-directed immunotherapy, or the use of a vaccine. Zeng et al (41) developed a DNA vaccine encoding MCPyV LT (pcDNA3-LT), which contained an LT-specific CD4 ${ }^{+}$T-helper epitope. This DNA vaccine generated antitumor effects that were predominantly mediated by $\mathrm{CD} 4^{+} \mathrm{T}$ cells against $\mathrm{LT}$ in mice (41).

\section{Conclusions}

$\mathrm{MCC}$ is an aggressive tumor with poor prognosis. Although surgical removal with negative margins, eventually followed by radiotherapy, remains the first-line treatment, immunotherapy appears to represent a very promising alternative approach. The identification of the MCPyV-specific cellular immune response has suggested novel therapeutic targets. In this respect, it would be helpful to identify MCPyV-positive patients among all the patients with MCC in order to optimize the use of antiviral therapy and DNA vaccines encoding MCPyV LT. Furthermore, particularly in the case of immunocompromised patients, such as organ transplant recipients and AIDS patients, prevention should not be discounted: Since UV exposure appears to be associated with the etiology of MCC, these patients should consequently limit their exposure to UV radiation and adopt sun safety practices. However, one single approach is not likely to be effective for all the patients, due to the inter-individual variability of the immune system and the mechanisms of immune evasion for MCC. Therefore, further studies are required to investigate multiple target therapies and to improve our understanding of the molecular mechanisms of immune evasion.

\section{References}

1. Samimi M and Touzé A: Merkel cell carcinoma: The first human cancer shown to be associated with a polyomavirus. Presse Med 43: e405-e411, 2014.

2. Jankowski M, Kopinski P, Schwartz R and Czajkowski R: Merkel cell carcinoma: Is this a true carcinoma? Exp Dermatol 23: 792-794, 2014.

3. Morrison KM, Miesegaes GR, Lumpkin EA and Maricich SM: Mammalian Merkel cells are descended from the epidermal lineage. Dev Biol 336: 76-83, 2009.

4. Zur Hausen A, Rennspiess D, Winnepenninckx V, Speel EJ and Kurz AK: Early B-cell differentiation in Merkel cell carcinomas: Clues to cellular ancestry. Cancer Res 73: 4982-4987, 2013.

5. Bichakjian CK, Lowe L, Lao CD, Sandler HM, Bradford CR, Johnson TM and Wong SL: Merkel cell carcinoma: Critical review with guidelines for multidisciplinary management. Cancer 110: 1-12, 2007.

6. Agelli M and Clegg LX: Epidemiology of primary Merkel cell carcinoma in the United States. J Am Acad Dermatol 49: 832-841, 2003.

7. Afanasiev OK, Yelistratova L, Miller N, Nagase K, Paulson K, Iyer JG, Ibrani D, Koelle DM and Nghiem P: Merkel polyomavirus-specific T cells fluctuate with merkel cell carcinoma burden and express therapeutically targetable PD-1 and Tim-3 exhaustion markers. Clin Cancer Res 19: 5351-5360, 2013.

8. Heath M, Jaimes N, Lemos B, Mostaghimi A, Wang LC, Peñas PF and Nghiem P: Clinical characteristics of Merkel cell carcinoma at diagnosis in 195 patients: The AEIOU features. J Am Acad Dermatol 58: 375-381, 2008.

9. Albores-Saavedra J, Batich K, Chable-Montero F, Sagy N, Schwartz AM and Henson DE: Merkel cell carcinoma demographics, morphology, and survival based on 3870 cases: A population based study. J Cutan Pathol 37: 20-27, 2010.

10. Becker JC: Merkel cell carcinoma. Ann Oncol 21 (Suppl 7): vii81-vii85, 2010.

11. Lunder EJ and Stern RS: Merkel-cell carcinomas in patients treated with methoxsalen and ultraviolet A radiation. $\mathrm{N}$ Engl J Med 339: 1247-1248, 1998.

12. Wooff JC, Trites JR, Walsh NM and Bullock MJ: Complete spontaneous regression of metastatic merkel cell carcinoma: A case report and review of the literature. Am J Dermatopathol 32: 614-617, 2010.

13. Burack J and Altschuler EL: Sustained remission of metastatic Merkel cell carcinoma with treatment of HIV infection. J R Soc Med 96: 238-239, 2003.

14. Chang Y and Moore PS: Merkel cell carcinoma: A virus-induced human cancer. Annu Rev Pathol 7: 123-244, 2012. 
15. Feng H, Shuda M, Chang Y and Moore PS: Clonal integration of a polyomavirus in human Merkel cell carcinoma. Science 319: 1096-1100, 2008.

16. Kuwamoto S: Recent advances in the biology of Merkel cell carcinoma. Hum Pathol 42: 1063-1077, 2011.

17. Foulongne V, Kluger N, Dereure O, Mercier G, Molès JP, Guillot B and Segondy M: Merkel cell polyomavirus in cutaneous swabs. Emerg Infect Dis 16: 685-687, 2010.

18. Schowalter RM, Pastrana DV, Pumphrey KA, Moyer AL and Buck CB: Merkel cell polyomavirus and two previously unknown polyomaviruses are chronically shed from human skin. Cell Host Microbe 7: 509-515, 2010.

19. Loyo M, Guerrero-Preston R, Brait M, Hoque MO, Chuang A Kim MS, Sharma R, Liégeois NJ, Koch WM, Califano JA, et al: Quantitative detection of Merkel cell virus in human tissues and possible mode of transmission. Int J Cancer 126: 2991-2966, 2010.

20. Kantola K, Sadeghi M, Lahtinen A, Koskenvuo M, Aaltonen LM, Möttönen M, Rahiala J, Saarinen-Pihkala U, Riikonen P, Jartti T, et al: Merkel cell polyomavirus DNA in tumor-free tonsillar tissues and upper respiratory tract samples: Implications for respiratory transmission and latency. J Clin Virol 45: 292-295, 2009.

21. Babakir-Mina M, Ciccozzi M, Lo Presti A, Greco F, Perno CF and Ciotti M: Identification of Merkel cell polyomavirus in the lower respiratory tract of Italian patients. J Med Virol 82: 505-509, 2010.

22. Bialasiewicz S, Lambert SB, Whiley DM, Nissen MD and Sloots TP: Merkel cell polyomavirus DNA in respiratory specimens from children and adults. Emerg Infect Dis 15: 492-494, 2009.

23. Goh S, Lindau C, Tiveljung-Lindell A and Allander T: Merkel cell polyomavirus in respiratory tract secretions. Emerg Infect Dis 15: 489-491, 2009.

24. Bhatia S, Afanasiev O and Nghiem P: Immunobiology of Merkel cell carcinoma: Implications for immunotherapy of a polyomavirus-associated cancer. Curr Oncol Rep 13: 488-497, 2011.

25. Spurgeon ME and Lambert PF: Merkel cell polyomavirus: A newly discovered human virus with oncogenic potential. Virology 435: 118-130, 2013.

26. Shuda M, Feng H, Kwun HJ, Rosen ST, Gjoerup O, Moore PS and Chang Y: T antigen mutations are a human tumor-specific signature for Merkel cell polyomavirus. Proc Natl Acad Sci USA 105: 16272-16277, 2008.

27. Shuda M, Chang Y and Moore PS: Merkel cell polyomavirus positive Merkel cell carcinoma requires viral small T antigen for cell proliferation. J Invest Dermatol 134: 1479-1481, 2014.

28. Bichakjian CK, Olencki T, Alam M, Andersen JS, Berg D, Bowen GM, Cheney RT, Daniels GA, Glass LF, Grekin RC, et al: Merkel cell carcinoma, version 1.2014. J Natl Compr Canc Netw 12: 410-424, 2014.
29. Chawla-Sarkar M, Lindner DJ, Liu YF, Williams BR, Sen GC, Silverman RH and Borden EC: Apoptosis and interferons: Role of interferon-stimulated genes as mediators of apoptosis. Apoptosis 8: 237-249, 2003.

30. Willmes C, Adam C, Alb M, Völkert L, Houben R, Becker JC and Schrama D: Type I and II IFNs inhibit Merkel cell carcinoma via modulation of the Merkel cell polyomavirus T antigens. Cancer Res 72: 2120-2128, 2012.

31. Olieman AF, Liénard D, Eggermont AM, Kroon BB, Lejeune FJ, Hoekstra HJ and Koops HS: Hyperthermic isolated limb perfusion with tumor necrosis factor alpha, interferon gamma, and melphalan for locally advanced nonmelanoma skin tumors of the extremities: A multicenter study. Arch Surg 134: 303-307, 1999.

32. Rosenberg SA, Restifo NP, Yang JC, Morgan RA and Dudley ME: Adoptive cell transfer: A clinical path to effective cancer immunotherapy. Nat Rev Cancer 8: 299-308, 2008.

33. Viral Oncoprotein Targeted Autologous T Cell Therapy for Merkel Cell Carcinoma. In: Clinicaltrials.gov. Bethesda (MD): National Library of Medicine, 2014.

34. https://www.clinicaltrialsregister.eu/ctr-search/trial/2013-000043$78 / \mathrm{DE}$

35. Hoos A: Development of immuno-oncology drugs-from CTLA4 to PD1 to the next generations. Nat Rev Drug Discov 15: 235-247, 2016.

36. Shah MH, Lorigan P, O'Brien ME, Fossella FV, Moore KN, Bhatia S, Kirby M and Woll PJ: Phase I study of IMGN901, a CD56-targeting antibody-drug conjugate, in patients with CD56-positive solid tumors. Invest New Drugs 34: 290-299, 2016.

37. Kim $\mathbf{J}$ and McNiff JM: Nuclear expression of survivin portends a poor prognosis in Merkel cell carcinoma. Mod Pathol 21: 764-769, 2008

38. Dresang LR, Guastafierro A, Arora R, Normolle D, Chang Y and Moore PS: Response of Merkel cell polyomavirus-positive merkel cell carcinoma xenografts to a survivin inhibitor. PLoS One 8: e80543, 2013.

39. Shah MH, Varker KA, Collamore M, Zwiebel JA, Coit D, Kelsen D and Chung KY: G3139 (Genasense) in patients with advanced merkel cell carcinoma. Am J Clin Oncol 32: 174-179, 2009.

40. Verhaegen ME, Mangelberger D, Weick JW, Vozheiko TD, Harms PW, Nash KT, Quintana E, Baciu P, Johnson TM, Bichakjian CK and Dlugosz AA: Merkel cell carcinoma dependence on bcl-2 family members for survival. J Invest Dermatol 134: 2241-2250, 2014.

41. Zeng Q, Gomez BP, Viscidi RP, Peng S, He L, Ma B, Wu TC and Hung CF: Development of a DNA vaccine targeting Merkel cell polyomavirus. Vaccine 30: 1322-1329, 2012. 